\title{
The analysis of distribution of the reaction mixture in ammonia oxidation reactor
}

\author{
Bartosz Moszowski ${ }^{1}$, Tomasz Wajman ${ }^{2}$, Krzysztof Sobczak ${ }^{2}$, Marek Inger ${ }^{3 *}$, Marcin Wilk ${ }^{3}$ \\ ${ }^{1}$ Grupa Azoty Zakłady Azotowe Kędzierzyn S.A., ul. Mostowa 30 A, 47-220 Kędzierzyn-Koźle, Poland \\ ${ }^{2}$ Lodz University of Technology, Institute of Turbomachinery, ul. Wólczańska 219/223, 90-924 Łódź, Poland \\ ${ }^{3}$ New Chemical Syntheses Institute, al. Tysiaclecia Państwa Polskiego 13A, 24-110 Puławy, Poland \\ *Corresponding author: e-mail: marek.inger@ins.pulawy.pl
}

\begin{abstract}
This article describes the influence of various design modifications of the ammonia oxidation reactor operating in nitric acid plant TKIV in Kędzierzyn-Koźle on flow distribution of an air-ammonia mixture. The CFD (Computational Fluid Dynamics) simulations of turbulent flow were carried out with SST k- $\omega$ turbulence model to close the system of RANS (Reynolds Averaged Navier-Stokes) equations. The simulation results show that the properly selected perforated plate screen and the conical diffuser ensure uniform flow of gas on the ammonia oxidation catalysts and on the catalysts for nitrous oxide decomposition. It was proved experimentally achieving uniform temperature of nitrous gases in different locations under the catalytic gauzes and high efficiency of ammonia oxidation and nitrous oxide decomposition
\end{abstract}

Keywords: Nitric acid, ammonia oxidation reactor, flow distribution, CFD simulation.

\section{INTRODUCTION}

Nitric acid is an important product of large-scale chemical industry. It is mainly used to produce fertilizers. The technology based on Ostwald process has been known for more than one hundred years ${ }^{1-3}$.

Nowadays, two plants called TKIV and TKV, both based on dual pressure technology work in Grupa Azoty ZAK S.A. The nitric acid plant TKV was designed and delivered by Chemoprojekt a.s./Czech Republic and started-up in 2010/2011 ${ }^{4}$. The second one TKIV started-up in 1995. Its daily capacity is $530 \mathrm{t} / 24 \mathrm{~h}$ per $100 \%$ nitric acid.

Ammonia oxidation in the nitric acid plant TKIV is carried out under the gauge pressure of $0.38 \mathrm{MPa}$, whereas absorption is carried out under the gauge pressure of 1.1 MPa. Raw materials for producing nitric acid with the concentration of $60 \pm 3 \%$ wt. are: ammonia, air and water. Ammonia is fed into the plant in the liquid form. The atmospheric air undergoes the duel filtration process and it is divided into two streams: the primary air which is directed into mixer and so called "secondary air" which is directed into the bleaching tower. Additionally, a small amount of air is fed into nitrous gas stream in order to accelerate oxygenation of NO to $\mathrm{NO}_{2}$. Oxidation of ammonia to nitrous oxide is carried out at the temperature of $890^{\circ} \mathrm{C}$ with the efficiency of $96-97 \% \%^{5-6}$. The heat of nitrous gases is used for production of steam with the pressure of approx. 2.5 MPa. Nitrous gases cooled in heat exchangers are directed into the absorption column. In this column, the parallel reactions of $\mathrm{NO}_{2}$ absorption in water and oxidation of secondarily formed $\mathrm{NO}$ to $\mathrm{NO}_{2}$ take place. The formed nitric acid solution after prior degassing and removal of nitrogen oxides, so called bleaching of the nitric acid, is directed to the storage tank. Gases after absorption, so called tail gases are decompressed in the expansion turbine and then released into the atmosphere through the chimney.

The basic reaction in nitric acid technology is the catalytic oxidation of ammonia. Usually, platinum-rhodium catalyst gauzes with variable thickness of mesh, most frequently with diameter of $0.06-0.92 \mathrm{~mm}$ and variable density of knitting, most frequently of 1024 meshes/ $\mathrm{cm}^{2}$ are used as a catalyst ${ }^{5-6}$. These gauzes are placed in the reactor with the diameter of 2-6 m. Currently, apart from catalyst for ammonia oxidation, the second catalyst is applied in the reactor in order to decompose a greenhouse gas - nitrous oxide which is formed as a byproduct during ammonia oxidation ${ }^{7}$. Exploitation of gauzes has a significant impact on cost-effectiveness of the nitric acid production process. During exploitation, the efficiency of oxidation of $\mathrm{NH}_{3}$ to $\mathrm{NO}$ is gradually lowered ${ }^{8}$. The determination of life-time of catalyst gauzes operation in the plant, so-called campaign duration, depends on the process parameters (pressure, temperature; and catalyst load) and it is the subject to optimization. It is necessary to ensure proper operational parameters including provision of feedstock (ammonia, air) free from impurities and to provide its uniform distribution on the entire surface of gauzes. The reaction mixture composed of ammonia and air with a given stable ratio at the relevant temperature and pressure (p, T) is fed into the feeding pipeline. The reactor's diameter is several times bigger than the feeding pipeline diameter. Therefore, it is necessary to apply a special design of the burner's head in order to ensure uniform distribution of gas onto the entire surface of catalyst gauzes. Improper mixing of ammonia with air and mal-distribution of airammonia mixture can directly affect suboptimal work of the reactor and catalyst. Long-term local overloading of a catalyst package can lead to its overheating and to the increased catalyst losses, and as a consequence, to the excessive lowering of $\mathrm{NH}_{3}$ to $\mathrm{NO}$ oxidation efficiency.

The supplier of TKIV nitric acid plant did not provide the license for producing nitric acid and the process was developed by Instytut Nawozów Sztucznych in Puławy (now Instytut Nowych Syntez Chemicznych) and Biuro Projektowo-Konstrukcyjne in Kedzierzyn Koźle (BPK). A number of detailed designs of equipment were developed in order to ensure an effective operation of the plant. 
This unit is characteristic of low ammonia consumption and low impact on the environment. Thanks to the solutions applied, it meets all requirements of modern nitric acid plant contained in Best Available Techniques BAT with a large safety margin?.

The CFD RANS (Reynolds Averaged Navier-Stokes Computational Fluid Dynamics) simulations is a useful tool for modelling fluid flows in chemical engineering. It is used for prediction of distribution of flow parameters (including temperature) in different types of reactors ${ }^{\mathbf{1 0 - 1 1}}$, hydrocyclones ${ }^{12}$ and boilers in power plants ${ }^{13-15}$. The CFD RANS simulations allow for determination of a flow structure and they enable to verify the influence of design modifications in case of inadequate reactor operation.

\section{Simulation definition (Experimental)}

This paper presents the analysis of the effect of various designs of the burner head (application of screens made of perforated plates, cone diffuser and guide vanes) on making the flow through catalyst gauzes uniform in the reactor operating in nitric acid plant TKIV. The simulation domain geometry was developed based on basic engineering documentation of the reactor and it included: the inlet pipe with the elbow feeding the gas from the ammonia and air mixer, the elbow feeding the gas to the reactor composed of the conical and cylindrical parts and the packet of catalyst gauzes as well as the catalyst layer for $\mathrm{N}_{2} \mathrm{O}$ decomposition. The general view of the domain was presented in Fig. 1. The primary configuration did not include elements which would make the flow structure uniform. In next stages of CFD RANS simulations, elements making the flow uniform were included such as: internal diffuser, perforated plate screen and guide vanes placed in the feeding elbow (Fig. 2).

Steady state simulations of the flow in the inlet pipeline and in the burner head were done using the ANSYS CFX solver. The flow was turbulent with Reynolds number ranging from $\mathrm{Re}=3.66 \cdot 10^{5}$ in the cylindrical part of the burner head to $\operatorname{Re}=1.74 \cdot 10^{6}$ at the pipeline inlet. Therefore a set of RANS (Reynolds Averaged Navier-Stokes) equations was solved with SST (Shear Stress Transport) turbulence model. Due to low flow velocity of gas, the fluid was treated as incompressible with parameters (temperature, pressure, density, viscosity) for the ammonia-air mixture fed to the reactor. As the heat transfer to the reactor wall was neglected and no

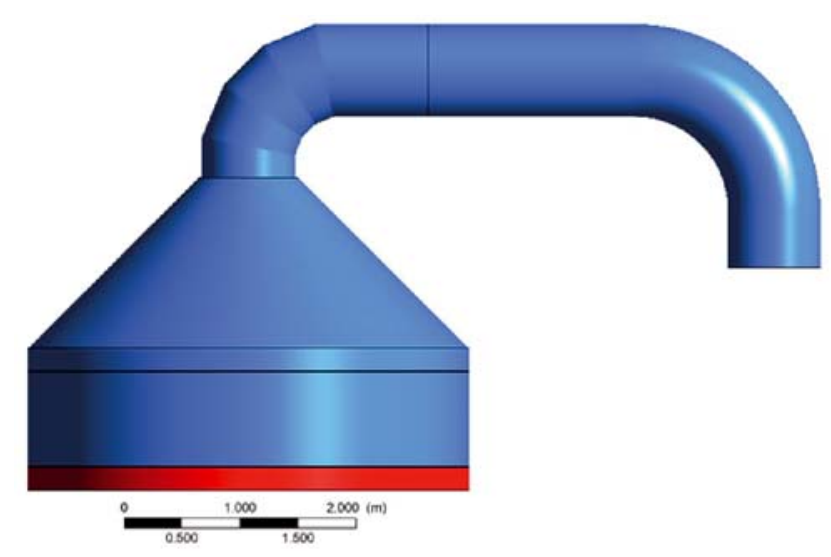

Figure 1. Calculation domain geometry

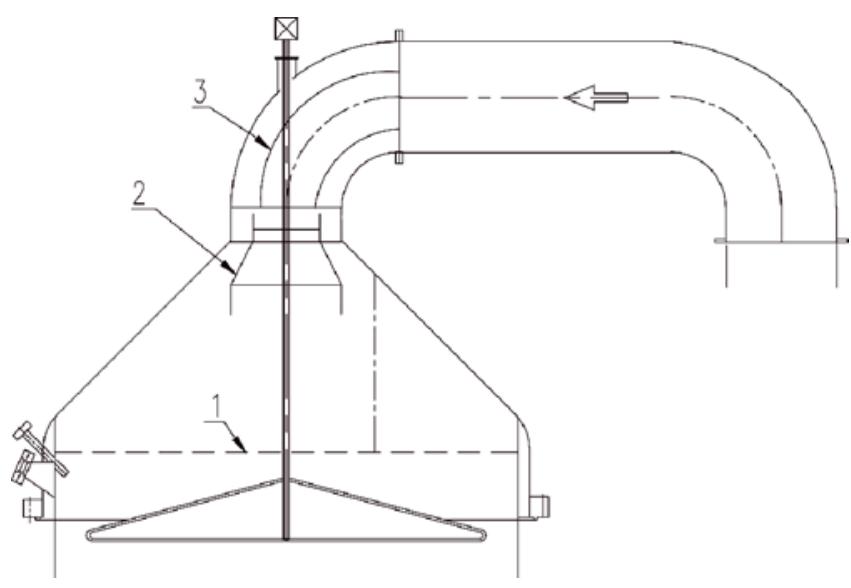

Figure 2. Cross-section of the burner head with marked elements: 1 - the perforated plate screen 2 - conical diffuser, 3 - guide vanes

chemical reaction was considered, the flow was treated as isothermal $(\mathrm{T}=481.8 \mathrm{~K})$.

A complete, detailed solution of the flow structure through the holes of the perforated plate screen, catalyst gauze and catalyst bed was not taken into account due to its huge computing requirements. However, simplified simulations were successfully carried out where these elements were treated as porous material layers with thicknesses corresponding to the real thicknesses of these elements. The resistance coefficient of porous layer substituting the screen was $\zeta=1018$ and it was equivalent to the perforated plate $3 \mathrm{~mm}$ thick, with holes of $\varphi=$ $8 \mathrm{~mm}$ in diameter and their square layout every $32 \mathrm{~mm}$.

Parameters assumed to the model of the porous layers substituting the catalysts are as follows: catalytic gauze: porosity $\varepsilon=0.5$ and permeability $\varkappa=0.556 \cdot 10^{-9} \mathrm{~m}^{2}$, catalyst $\mathrm{deN}_{2} \mathrm{O}$ : porosity $\varepsilon=0.421$ and permeability $x=1.953 \cdot 10^{-9} \mathrm{~m}^{2}$. These values result from the real pressure drops in two catalysts which were $\Delta \mathrm{p}_{1}=100$ $\mathrm{Pa}$ and $\Delta \mathrm{p}_{2}=3400 \mathrm{~Pa}$, respectively.

The boundary condition for total pressure equal to 0,48 MPa was imposed at the pipe inlet.

The outlet boundary condition with the mass flow rate corresponding to the flow rate equal to $80280 \mathrm{Nm}^{3} / \mathrm{h}$ was assumed. Side walls of the reactor were assumed as smooth. A good quality numerical solution was reached with RMS (Root Mean Square) residuals of the transport equation below $2 \cdot 10^{-5}$ as well as the imbalance of mass and momentum flows below $0.05 \%$ (numerical imbalance at the domain boundaries versus a maximum flow value).

\section{RESULTS}

The major objective of the project was to analyze the gas velocity distribution in the reactor, the aim of which is to maximize the operation time of catalyst gauzes. Three different arrangements of the burner head were studied in order to verify their impact on the uniformity of the velocity of the fluid stream entering the catalysts. Simulations results were presented in Figs. 3, 4 and 5.

\section{Simulation I}

In this simulation, the conical internal diffuser was used as an element contributing to the stream alignment. However, due to disturbances generated in the elbows (secondary flows and separations) the velocity 
determined at the burner head is highly non-uniform (Fig. 3). Locally, the highest velocity value is observed near the inlet edge of conical diffuser. Such a location of the diffuser cone causes only slight straightening of the main gas stream flowing to the reactor. Strong inertia forces causes deflection of the gas jet entering the reactor from the axis of the burner head toward the diffuser wall at the external radius side of the second elbow. Approx. 30\% of the gas flows between the diffuser and the reactor wall. Inside the conical head, the flowing gas stream is highly non-uniform. The clear jet is observed, and despite the fact that some diffusion effect can be observed along the flow path, the flow velocity on the catalyst gauzes ranges from 0.2 to $6.3 \mathrm{~m} / \mathrm{s}$. Due to resistance of the catalytic gauze, a significant part of the fluid jet is reflected, and large vortex structures are formed in the burner head.
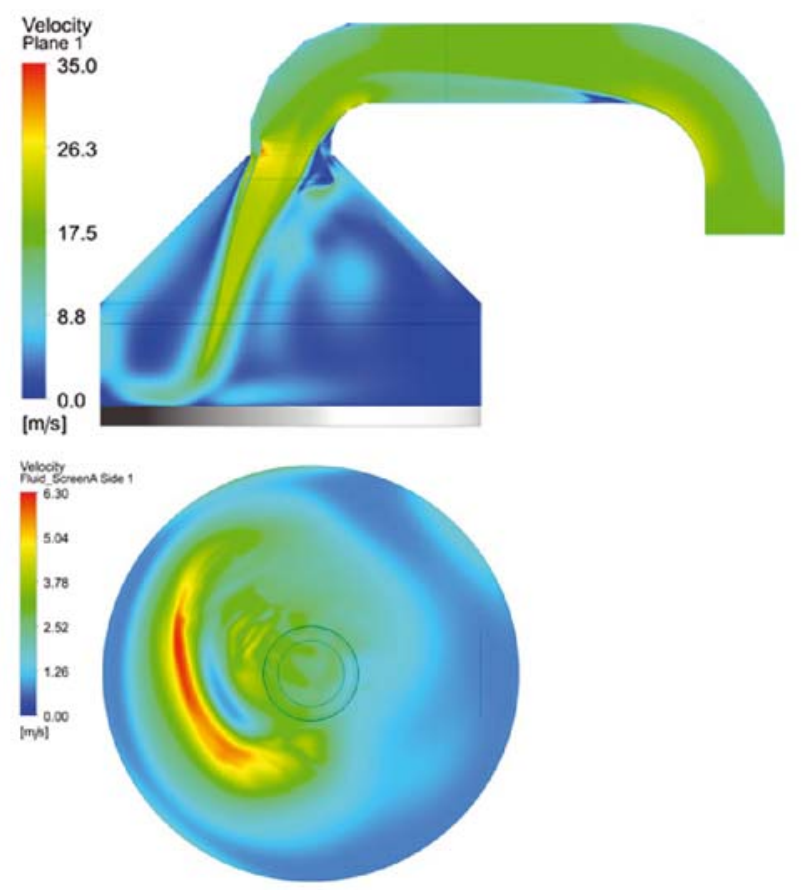

Figure 3. Velocity distribution on the symmetry plane of the burner head (top) and the catalytic gauze (bottom) for simulation I

\section{Simulation II}

The perforated plate screen placed at the outlet of the conical burner head was added in the second design configuration. As there is no modification of the conical burner head, the distribution of gas velocity in the inlet pipeline and behind diffuser cone is similar to the one in the previous case. There is a high pressure drop of $930 \mathrm{~Pa}$ on the perforated plate screen and the jet is mainly deflected due to its relatively low porosity. As in the previous case, large vortex structures are formed in the burner head. However, high resistance of the screen causes the flow velocity downstream of this element to be much more uniform. The gas flow velocity beneath the screen in the whole cross-section ranges from 0.65 to $0.95 \mathrm{~m} / \mathrm{s}$. The further stream straightening is observed due to catalyst resistance and the velocity of the fluid entering the catalytic gauze ranges from 0.72 to $0.76 \mathrm{~m} / \mathrm{s}$.

\section{Simulation III}

In this design, the guide vanes were added in the elbow of the inlet pipeline. They have a significant effect on the flow structure uniformity at the entrance of the conical diffuser. However, these vanes affect the general performance of the burner head only to a small degree. Due to higher uniformity of the flow at the entrance of the conical head, the jet flow is almost symmetrical along the burner axis and the conical diffuser works more effectively. However, due to huge angle of the burner head, separations of the flow at walls are still present. It is obvious that for such a wide angle of the head, it is not possible to make the flow uniform. Thus, the screen with relatively high resistance (pressure drops) is indispensable. The gas flow velocity beneath the screen is similar as in the previous case and it ranges from 0.65 to $0.95 \mathrm{~m} / \mathrm{s}$ but is more axially uniform. The gas velocity on the surface of catalyst is not much different than in the previous case being from 0.71 to $0.77 \mathrm{~m} / \mathrm{s}$.

The design composed of the perforated plate screen and the conical diffuser was used in the TKIV plant. As a result, a uniform distribution of the flow through ammonia oxidation catalyst is achieved. Therefore, the same temperature of nitrous gases was measured with three thermocouples located in different positions in ammonia oxidation reactor directly under the catalytic gauzes. During exploitation, the temperature difference does not exceed $5^{\circ} \mathrm{C}$.

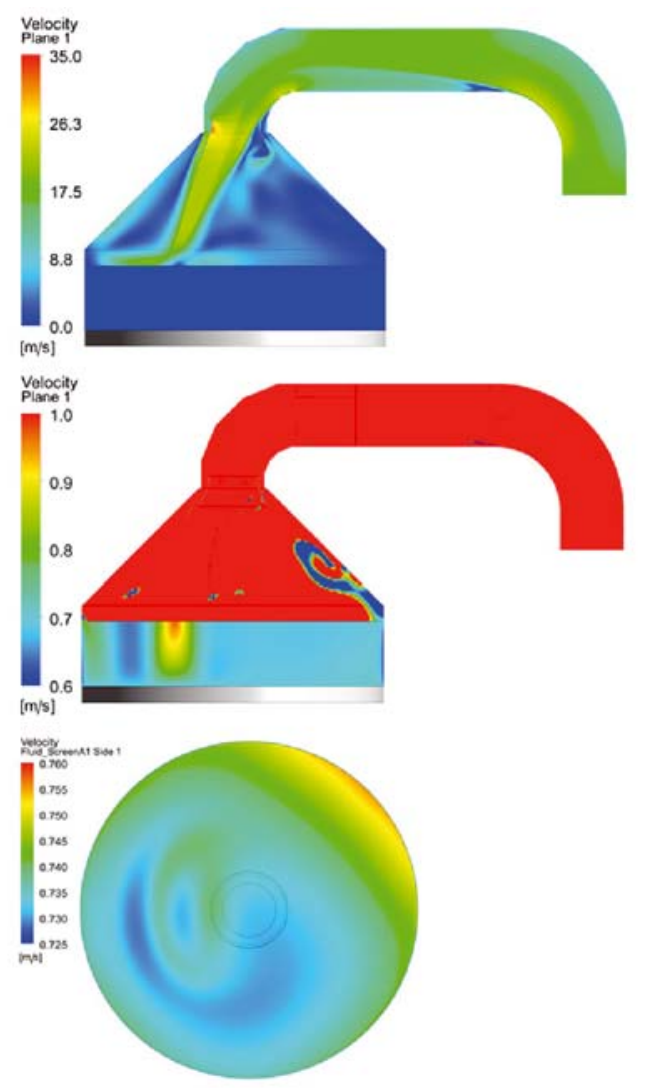

Figure 4. Velocity distribution on the symmetry plane of the burner head (top and middle) and the catalytic gauze (bottom) for simulation II 


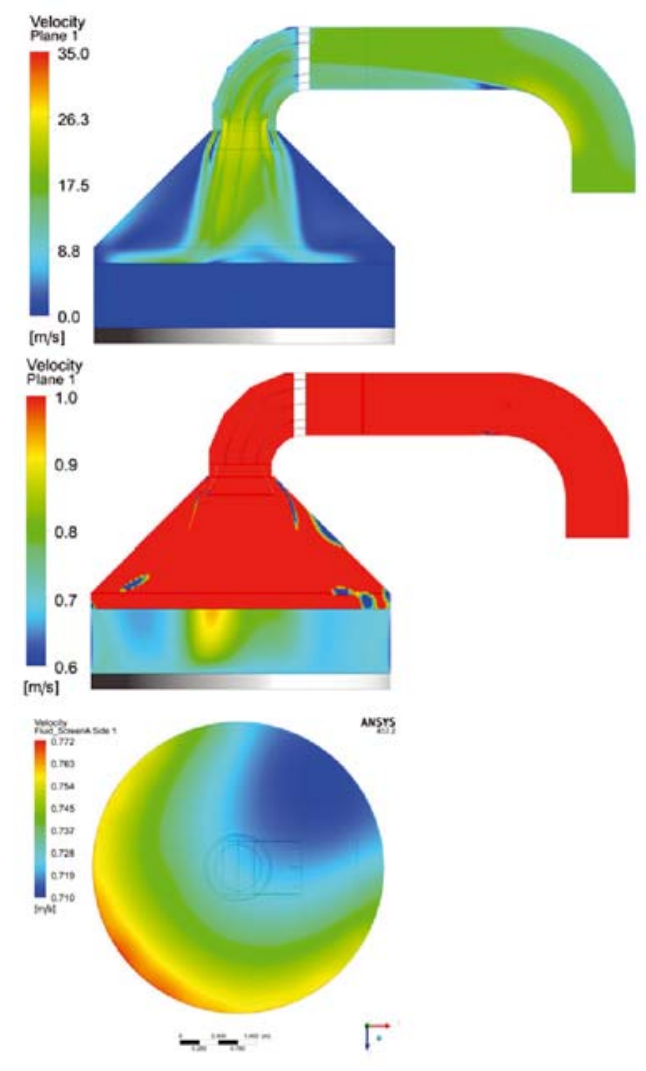

Figure 5. Velocity distribution on the symmetry plane of the burner head (top and middle) and the catalytic gauze (bottom) for simulation III

\section{CONCLUSIONS}

A wide angle of the burner head makes it difficult to achieve the uniform flow in this element. The internal conical diffuser failed to expand the gas stream and it globally influenced the head performance to a very small degree. The additional application of the guide vanes in the elbow of the inlet pipe influenced the flow, making it more axially symmetrical, but it did not prevent separations at the burner walls. Thus, the application of the perforated plate screen with relatively high resistance was indispensable to achieve high flow uniformity through the catalyst bed. It did not straighten the fluid flow in the conical part of the burner head, but it highly reduced non-uniformities beneath.

It was found out that the accurately selected perforated plate and the conical diffuser solved the problem of ensuring the proper flow of gas on ammonia oxidation catalysts and catalysts for nitrous oxide decomposition. It was confirmed with the achievement of the identical temperature of nitrous gases in different spots under the catalytic gauzes and high efficiency of ammonia oxidation and nitrous oxide decomposition.

\section{LITERATURE CITED}

1. Praca zbiorowa. (1956). Technologia Związków Azotowych, tom II. Część I Kwas azotowy. PWT Warszawa, 35-182 [in Polish].

2. Ullman's Encyclopedia of Industrial Chemistry (2002) Wiley-VCH Verlag GmbH \& Co. KGaA. DOI: 10.1002/14356007. a17_293.
3. Schmidt-Szałowski, K., Szafran, M., Bobryk, E. \& Sentek, J. (2013) Technologia Chemiczna. Przemysł Nieorganiczny. PWN, 238-242 [in Polish].

4. Moszowski, B. \& Wolff, E. (2013). Experience gained during the mechanical and technological start-up of the nitric acid production plant. Przem. Chem. 92, 2207-2210. [in Polish].

5. Marret, S. \& du Chatelier, L. (1998). Recent advances in catalyst technology used in nitric acid production. The Fertiliser Society Proceedings No. 413.

6. Reference Document on Best Available Techniques for the Manufacture of Large Volume Inorganic Chemicals - Ammonia, Acids and Fertilisers, Chapter 3 Nitric Acid, European Commission Document (2007). http://eippcb.jrc.es

7. Perez-Ramirez, J., Kapteijn, F., Schoffel, K. \& Moulijn, J.A. (2003). Formation and control of $\mathrm{N}_{2} \mathrm{O}$ in nitric acid production Where do we stand today? Appl. Catal. B 44 117-151. DOI: 10.1016/S0962-3373(03)00026-2.

8. Kay, O. \& Buennagel, T. (2016) Targeting improving performance and conversion efficiency in nitric acid plants. International Fertiliser Society Proceedings No. 787.

9. Najlepsze dostępne techniki (BAT). Wytyczne dla Branży Chemicznej w Polsce. Przemysł Wielkotonażowych Chemikaliów Nieorganicznych, Amoniaku, Kwasów i Nawozów Sztucznych Wersja II, Ministerstwo Środowiska, (2005) [in Polish]. http:// www.pipc.org.pl/pl/download/bat/branza_chemiczna/2005-09-29/ nawozy_II.pdf

10. Ābbasfard, H., Ghanbari, M., Ghasemi, A., Ghahraman, G., Jokar, S.M. \& Rahimpour, M.R. (2014) CFD modelling of flow mal-distribution in an industrial ammonia oxidation reactor: A case study. Applied Thermal Engineering, 67, 223-229. DOI: 10.1016/j.applthermaleng.2014.03.035.

11. Wen, Z. \& Petera, J. (2015) CFD Numerical Simulation of Hydrodynamics in a Rotor-Stator Reactor for Biodiesel Synthesis. J. Appl. Mathem. Physics, 3, 997-1002. DOI: http:// dx.doi.org/10.4236/jamp.2015.38122.

12. Udaya Bhaskar, K., Rama Murthy, Y., Ravi Raju, M., Tiwari, S., Srivastava, J.K. \& Ramakrishnan, N. (2007) CFD simulation and experimental validation studies on hydrocyclone Min. Engin. 20, 60-71. DOI: 10.1016/jmineng.2006.04.012.

13. Zhang, N., Lu, B., Wang, W. \& Li, J. (2010) 3D CFD simulation on hydrodynamics of a $150 \mathrm{MW}_{\mathrm{e}}$ circulating fluidized bed boiler. Chem. Engine. J. 162, 821-828, DOI: 10.1016/j. cej.2010.06.033.

14. Kosmadakis, G.M., Rakopoulos, C.D., Demuynck, J., De Paepe, M. \& Verhelst, S. (2012) CFD modeling and experimental study of combustion and nitric oxide emissions in hydrogen-fueled spark-ignition engine operating in a very wide range of EGR rates. Int. J. Hydrogen Energy, 37, 10917-10934. DOI: 10.1016/ijhydene.2012.04.067.

15. Ruszak, M, Inger, M., Wilk, M., Nieścioruk, J., Saramok, M., Kowalik, W., Rajewski, J., Wajman, T., Kacprzak, W. \& Tadasiewicz, D. (2017). The application of RANS CFD for design of SNCR technology for a pulverized coal-fired boiler. Polish J. Chem. Technol., 19, 2, 101-106. DOI: 10.1515pjct-2017-0035. 